\title{
PENGEMBANGAN FASILITAS PERTUMBUHAN SPIRITUAL PASIEN DI UNIT HEMODIALISA RUMAH SAKIT SANTA ELISABETH MEDAN
}

\author{
Rusmauli Lumban Gaol, Setiawan, Cholina Trisa Siregar \\ Email : marluga_cute@yahoo.com
}

\begin{abstract}
Standard Operating Procedure (SOP) of Spiritual Growth Facilitation (SGF) is developed to increase patients' spirituality. The SOP which develops intervention in SGF has to be carried out by nurses, especially in the Hemodialysis Unit of Santa Elizabeth Hospital, Medan. This research used to deployment Standard Operating Procedure (SOP). Nurse intervention that carry patien who is undergoing hemodialys. The research used action research method with with consisted of the stages of reconnaissance, planning, acting, observing, and reflecting. The data were gathered by conducting FGD, distributing quetionnaires, and participant observation. Therewere 10hemodialysis nurse as the participants. The gathered data wereanalyzed qualitatively and quantitatively. The qualitatively data is get from the result of FGD and the result of observation. While the qualitatively data that gatherd from qusetionnaire deployment. This research showed Standard Operating Procedure (SOP) of Spiritual Growth Facilitation that being a model of doing enchancement patient spiritual intervantion who is undergoing hemodialys in hemodialysis unit of Santa Elisabeth Medan. And the possitive impact for knowledge,skills, and act to carry patient who is undrgoing hemodialys. Researcher ask to management of Santa Elizabeth Medan to keep do supervition to elevation contribution SOP in hemodialys Santa Elizabeth Medan.
\end{abstract}

Keywords: SOP, Spiritual Growth Facilitation, Nurses in Hemodialysis Room

\begin{abstract}
Abstrak
Standar Prosedur Operasional (SPO)spiritual growth facilitation merupakan suatu panduan yang dikembangkan untuk meningkatkan spiritual pasien. SPO ini mengembangkan intervensi spiritual growth facilitation yang harus dilakukan oleh perawat, untuk mengembangkan spiritual growthfacilitationdi Unit Hemodialisa Rumah Sakit Santa Elisabeth Medan.Jenis penelitian yang digunakan adalah action research.Penelitian ini bertujuan untuk mengembangkan Standar prosedur operasional (SPO) intervensi perawat yang merawat pasien yang sedang menjalani hemodialisa dan dapat dijadikan sebagai panduan oleh perawat dalam merawat pasien yang sedang menjalani hemodialisa. Desain penelitian ini adalah action research yang terdiri dari tahapan reconnaissance, planning, acting, observing dan reflecting.Metode pengumpulan data dilakukan melalui FGD, penyebaran kuesioner, dan observasi partisipan.Participan dalam Penelitian ini sebanyak 10 perawat hemodialisa.Analisis data menggunakan metode kuantitatif dan kualitatif. Data kualitatif diperoleh melalui hasil FGD dan hasil observasi, sedangkan data kuantitatif yang dikumpulkan melalui penyebaran kuesioner. Penelitian ini telah menghasilkan Standar prosedur operasional (SPO)spiritual growth facilitation yang menjadi acuan dalam melakukan peningkatan intervensi spiritual pasienyang sedang menjalani hemodialisa di Unit Hemodialisa Rumah Sakit Santa Elisabeth Medandan berdampak positif terhadap pengetahuan, ketrampilan dan sikap merawat pasien yang sedang menjalani hemodialisa. Peneliti mengharapkan kepada pihak manajemen Rumah SakitSanta Elisabeth Medan agar terus melakukan supervisi untuk mengevaluasi pelaksanaan SPO di Unit HemodialisaRumah Sakit Elisabeth Medan.
\end{abstract}

Kata kunci: SPO, SGF, Perawat diRuangan Hemodialisa 


\section{PENDAHULUAN}

Keperawatan memandang manusia merupakan makhluk yang unik dan kompleks yang terdiri atas berbagai dimensi. Dimensi yang komprehensif pada manusia itu meliputi dimensi biologis (fisik), psikologis, sosial, kultural dan spiritual, sehingga dalam melakukan hubungan profesionalisme perawat klien sepatutnya dilakukan secara keseluruhan tanpa melupakan bagian-bagian yang lain (Barbara, 2008).

Perawat sebagai tenaga kesehatan yang profesional mempunyai kesempatan paling besar untuk memberikan pelayanan kesehatan yang komprehensif dengan membantu klien memenuhi kebutuhan dasar yang holistik. Perawat memandang klien sebagai mahluk bio-psiko-sosiokultural dan spiritual yang berespon secara holistik dan unik terhadap perubahan kesehatan atau pada keadaan kritis. Perawat berusaha untuk membantu memenuhi kebutuhan spiritual klien sebagai bagian dari kebutuhan yang menyeluruh, antara lainndengan memfasilitasi pemenuhan kebutuhan spiritual klien tersebut, walaupun perawat dan klien tidak mempunyai keyakinan spiritual atau keagamaan yang sama (Hamid, 2000 dalam Sumiadi, dkk.,2011).

Gagal ginjal kronis atau penyakit renal tahap akhir merupakan gangguan fungsi renal yang progresif dan irreversible dimana kemampuan tubuh gagal untuk mempertahankan metabolisme dan keseimbangan cairan dan elektrolit (Brunner \& Suddarth, 2002). Salah Satu terapi yang dapat memperpanjang hidup penderita Gagal ginjal stadium akhir ini adalah dengan hemodialisis yang bertujuan mengeluarkan toksik dari dalam darah dan mengeluarkan air yang berlebihan yang tidak dapat lagi dilakukan oleh ginjal. Keadaaan ketergantungan pada mesin hemodialisa seumur hidupnya serta penyesuaian klien.

Perubahan dalam kehidupan merupakan salah satu pemicu stress dan keputusasaan. Perubahan yang lain yang terjadi pada pasien yang menjalalani hemodialisa adalah ketidakpatuhan terhadap modifikasi diet, uji diagnostik dan pembatasan asupan cairan. Hal ini menunjukkan bahwa dampak stress lainnya pada pasien yang menjalani hemodialisa adalah dapat memperburuk kesehatan pasien dan menurunkan kualitas hidupnya. Selain itu pasien yang mengalami stress dan rasa keputusasaan ditandai dengan rasa kwatir yang berlebih, depresi, rasa putus asa, serta upaya bunuh diri. Insiden bunuh diri pada pasien hemodialisis (Siswanto, 2007).

Perawat dalam memberikan asuhan keperawatan tidak hanya memperhatikan aspek fisik saja tetapi meliputi pemenuhan kebutuhan dasar manusia baik kebutuhan biologis, sosialkultural yang utuh dan unik dan spiritual, Tetapi kenyataannya bahwa perawat kurang memperhatikan tentang aspek spiritual yang utuh dan unik. Hal ini didukung oleh penelitian yang dilakukan oleh Tanjung dan Salbiah (2011) di RSUD Deli serdang diperoleh mayoritas $(94,3 \%)$ pasien memiliki harapan yang tinggi tentang perilaku caring perawat dan sebagian besar $(78,6 \%)$ pasien merasa puas terhadap perilaku caring perawat. Berdasarkan hasil penelitian tersebut memperlihatkan bahwa belum sempurnanya perawat memenuhi kebutuhan spriritual pasien, untuk itu disarankan perawat lebih memperhatikan kebutuhan spiritual pasien sehingga dapat meningkatkan kepuasan pasien.

Hasil penelitian Purwaningsih,dkk (2013) menyatakan adanya Hubungan Perilaku Caring Perawat dengan Pemenuhan Kebutuhan Spiritual Pasien dari 5 orang perawat $(6,8 \%)$ yang mempersepsikan caring perawat memuaskan, terdapat 4 pasien $(5,4 \%)$ pemenuhan kebutuhan spiritual dirasakan kurang, 1 orang pasien $(1,4 \%)$ merasakan pemenuhan kebutuhan spiritual cukup. Pada saat mengalami rasa keputusasaan dan stress, individu akan mencari dukungan dari keyakinan agamanya. Dukungan perawat ini sangat diperlukan untuk dapat menerima keadaan sakit yang dialami (AL Jauziyah,2004). Kebutuhan spiritual merupakan kebutuhan yang dibutuhkan oleh setiap manusia. Seseorang dalam keadaan sakit, maka hubungannya dengan Tuhannya pun semakin dekat, mengingat seseorang dalam kondisi sakit menjadi lemah dalam segala hal, tidak ada yang mampu membangkitkannya dari kesembuhan, kecuali sang Pencipta. Perawat sebagai petugas kesehatan harus memiliki peran

utama dalam memenuhi kebutuhan spiritual. Perawat dituntut mampu memberikan pemenuhan yang lebih pada saat pasien kritis atau menjelang ajal (Hidayat. 2006).

Perawat dalam memberikan asuhan keperawatan tidak hanya memperhatikan aspek fisik saja tetapi meliputi pemenuhan kebutuhan dasar manusia baik kebutuhan biologis, sosialkultural yang utuh dan unik dan spiritual, Tetapi kenyataannya bahwa perawat kurang memperhatikan tentang aspek spiritual yang utuh dan unik. Hal ini didukung oleh penelitian yang dilakukan oleh Tanjung dan Salbiah (2011) di RSUD Deli serdang diperoleh mayoritas $(94,3 \%)$ pasien memiliki harapan yang tinggi tentang perilaku caring perawat dan sebagian besar $(78,6 \%)$ pasien merasa puas terhadap perilaku caring perawat. Berdasarkan hasil penelitian tersebut memperlihatkan bahwa belum sempurnanya perawat memenuhi kebutuhan spriritual pasien, untuk itu disarankan perawat lebih memperhatikan kebutuhan spiritual pasien sehingga dapat meningkatkan kepuasan pasien.

\section{METODE PENELITIAN}

Penelitian ini menggunakan action research $(A R)$. Penelitian ini melibatkan partisipasi yang aktif dari partisipasi untuk membuat Standar Prosedur Operasional atau Metode dalam Spiritual growth Facilitation. Desain penelitian ini adalah action research yang terdiri dari tahapan 
reconnaissance, planning, acting, observing dan reflecting. Metode pengumpulan data dilakukan melalui FGD, penyebaran kuesioner dan observasi partisipan.Participan dalam Penelitian ini sebanyak 10 perawat hemodialisa.Analisis data menggunakan metode kuantitatif dan kualitatif. Standar Prosedur Operasional (SPO) dirancang dapat diterapkan di Unit Hemodialisa Rumah sakit Elisabeth Medan. Action research terdiri dari 4 tahapan yaitu: reconnaissance, planning, action, dan observing and reflecting (Kemmis\&c Taggart,1988).

Kegiatan dalam siklus action research melibatkan partisipan dalam merencanakan kegiatan, melaksanakan kegiatan, mengamati dan memantau kegiatan, menganalisis masalah yang ditemukan dan akhirnya menyusun laporan kemajuan program pengembangan Spiritual Growth Facilitation. Pelaksanakan kegiatan dalam tahap pelitian action research dapat dilakukan pada periode yang sama. Kejadian tersebut terjadi karena jenis penelitian tidak kaku tetapi dapat ditingkatkan atau diubah sesuai dengan keadaan yang terjadi.

Penelitian ini dilakukan di Ruangan Hemodialisa Rumah Sakit Santa Elisabeth Medan. Lokasi penelitian ini dipilih berdasarkan pertimbangan hasil survey pendahuluan yang dilakukan oleh peneliti karena situasi diruangan ini dinilai dapat mendukung untuk dilakukan penelitian.

Waktu penelitian akan dimulai pada bulan April 2016 sampai dengan 2016. Pertimbangan waktu ini ditentukan karena penelitian harus menyesuaikan dengan metode action research yang memiliki siklus dengan beberapa tahapan sehingga membutuhkan waktu yang panjang agar mendapatkan hasil penelitian yang representatif. Partisipan dalam penelitian ini adalah orang-orang yang terlibat langsung dalam Pengembangan SPO yang dengan total jumlah 10 orang, terdiri atas kepala keperawatan, Kepala diklat, kepala ruangan, perawat pelaksana diruang hemodialisa Rumah Sakit Santa Elisabeth Medan. Tehnik yang digunakan dalam penelitian ini adalah purposive sampling.

Pengumpulan data dalam penelitian ini akan dilakukan oleh peneliti sendiri. Proses pengumpulan data terdiri atas metode dan alat pengumpulan data, yaitu: observasi,self report, FGD. Dan alat yang digunakan yaitu:

(1) voice recorder, (2)panduan wawancara,Focus Group Discussion (FGD) (3) Kuisioner pengetahuan tentang program SPO spiritual caring, (4) Kuisioner tingkat kepuasan perawat yang menjalani SPO, dan (5) lembar observasi dan (6) alat tambahan atau penunjang yaitu voice recorder

\section{HASIL PENELITIAN}

Hasil Penelitian ini telah menghasilkan Standar prosedur operasional (SPO) spiritual growth facilitation yang menjadi acuan dalam melakukan peningkatan intervensi spiritual pasien yang sedang menjalani hemodialisa di Unit Hemodialisa Rumah Sakit Santa Elisabeth Medan dan berdampak positif terhadap pengetahuan, ketrampilan dan sikap merawat pasien yang sedang menjalani hemodialisa.

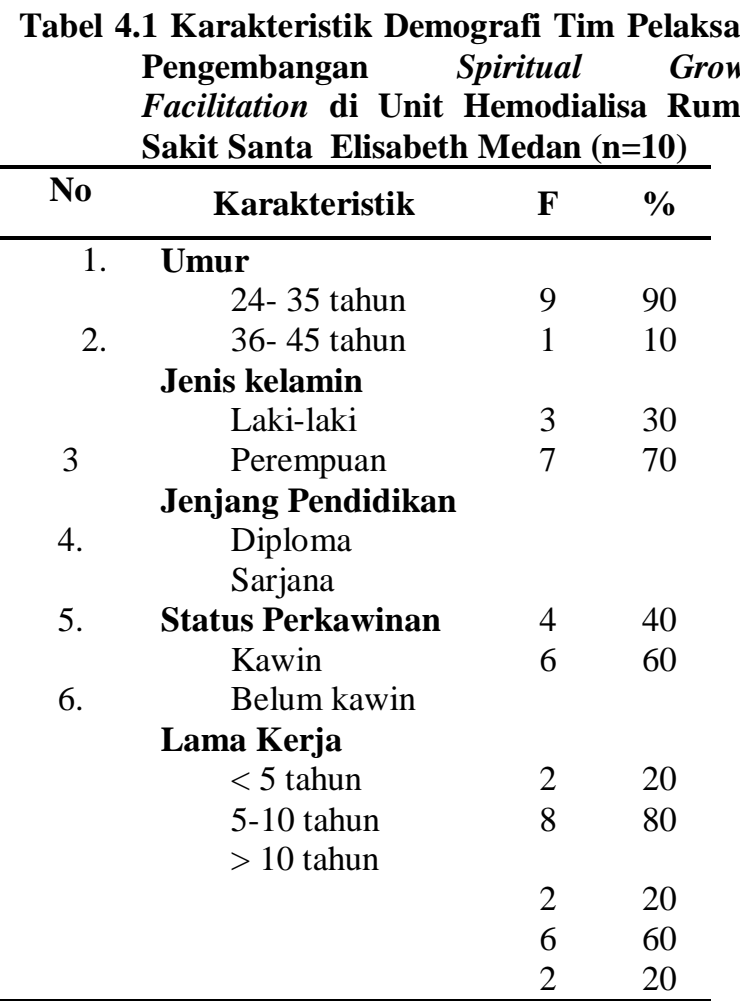

\section{Proses pengembangan SOP Spiritual Growth Facilitation (SGF)}

Proses pengembangan SPO-Spiritual Growth Facilitation dijelaskan menjadi 2 tahap. Tahap pertama adalah reconnaissance, Tahap ini menjelaskan mulai dari pendekatan kepada pihakpihak yang berkepentingan di lahan penelitian sampai dengan mendapatkan masalah untuk diteliti. Tahap kedua menjelaskan tentang tahap siklus action research mulai dari tahap planning, action, dan observation serta reflection.

\subsubsection{Tahapan reconnaissance}

Tahap reconnaissance dilaksanakan peneliti sejak bulan Pebruari 2016, Peneliti melakukan pendekatan dengan Kepala diklat dan pejabat struktur rumah sakit santa elisabeth medan untuk mendapatkan izin dan mendukung dilakukannya penelitian pengembangan spiritual pasien. Pengumpulan data awal tentang pengembangan spiritual pasien dilakukan dengan melakukan wawancara kepada partisipan tim perumus atau pelaksana padatahap reconnaissance dan self reportoleh partisipan perawat hemodialisa.

Hasil pengumpulan data pada tahap reconnaissance dikelompokan ke dalam tiga bagian yaitu (1) Konteks studi yang menggambarkan setting tempat penelitian dan partisipan, (2) Perspektif tim perumus atau pelaksana tentang SPO pengembangan 
spiritual pasien selama ini di rumah sakit dan (3) Perspektif perawat hemodialisa tentang pelaksanaan program SPO selama di Rumah Sakit Santa Elisabet Medan yang meliputi pengetahuan dan kepuasan.

Berikut penjelasan dari hasil reconnaissance, yaitu:

\section{1) Setting tempat penelitian dan partisipan.}

Penelitian in dilakukan diruangan Hemodialisa Rumah Sakit Santa Elisabeth Medan berada dilantai dua danterdiri satu unit perawatan dengan kapasitas tempat tidur yang terdiri dari 8 tempat tidur, 1 ruangan isolasi, 1 nurse station, ruang khusus kepala ruangan atau ruang TCD (Trans Cranial Dopler)/ konsultasi dokter, ruangan tempat penyimpanan peralatan laken, ruangan penyimpanan alat- alat kesehatan dan ruangan dapur dan ruangan AC memilik AC sebanyak 6 Unit dan 7 mesin hemodialisa, rata-rata jumlah pasien perbulan sebanyak 150 pasien,pasien rawat inap dan rawat jalan.

Jumlah perawat di unit hemodialisa sebanyak 10 orang dengan 9 orang perawat pelaksana dan 1 sebagai Ka. Ruangan hemodialisa dan 9 orang lain sebagai pelaksana.Pendidikan perawat DIII Keperawatan (5 Orang)dan S1 Keperawatan (5 orang ), pegawai tetap 9 orang dan 1 orang pegawai kontrak. Dalam memberikan pelayanan kepada pasien, pimpinan dan yayasan selalu menekankan agar mengutamakan pelayanan yang ramah dan teraupetik kepada setiap pasien dan kelurganya, karena menurut pimpinan hal tersebutlah yang harus diutamakan di rumah sakit tersebut untuk menarik perhatian masyarakat. Metode pelayanan perawatan yang dilaksanakan adalah metode fungsional yang terdiri dari 2 shift pagi dan siang.

\section{Perspektif Tim Perawat tentang Pengembangan Spiritual Growth Facilitation diRumah sakit santa elisabeth Medan}

Wawancara dengan tehnik FGD terhadap partisipan tersebut berdasarkan pada beberapa pokok bahasan yaitu 1) Pengertianspiritual growth facilitation SGF, 2) Tujuan dari pelaksanaan SGF, 3) Faktor pendukung SGF, 4) Manfaat SGF, 5) harapan terhadap SGF.

\section{Perspektif perawat hemodialisa tentang pelaksanaan SPO dalam pengembangan spiritual pasien yang meliputi pengetahuan dan kepuasan di rumah sakit santa elisabeth medan}

Berdasarkan hasil kuisioner kepuasan perawat tentangpelaksanaan SPO Spiritual growth facilitation pasien di rumah sakit santa elisabeth medan yang dibagikan kepada 10 orang perawat didapat hasil yaitu 7 perawat $(70 \%)$ merasa puas dan 3perawat $(30 \%)$ merasa cukup puas. Proses action research:

Pelaksanaan action research pada penelitian ini adalah satu siklus action research tentang pengembangan spiritual growth facilitation di Rumah
Sakit Santa Elisabeth Medan. melalui tahapan planning, action dan observation serta reflection. Setiap tahapan action research mencakup kegiatan yang dilakukan oleh peneliti. Kegiatan action research dilaksanakan selama 12 minggu di mulai dari tanggal 9 Mei sampai dengan 31 Agustus 2016. Berikut ini akan dijelaskan hasil kegiatan yang telah dilaksanakan pada masing-masing tahap.

\subsubsection{Tahap planning}

Tahap planningini dilakukan untuk menyusun rencana aksi atau rencana kegiatan yang kemudian dilaksanakan pada tahap penelitian berikutnya. Kegiatan planning dilaksanakan pada 2 minggu, Adapun rencana kegiatan (1)merencanakan pembentukan tim perumus SPO dalam pertemuan koordianasi(2) merencanakan seminar dan sosialisasi tentang spiritual growth facilitationyang harus dilskuksn oleh perawat, (3) merencanakan pembuatan Standar Prosedur Operasional (SPO) dan format observasi progran spiritual caring. Pada tahap ini peneliti dan partisipan berhasil menyusun rencana yang sesuai dengan hasil yang ditemukan pada tahap reconnaissance.

\subsubsection{Tahap Action}

Tahapan Action di lakukan dengan berkesinambungan dengan lama waktu 10 minggu. Pada tahap Action, lain yaitu pembentukan tim kegiatan antara inipembentukan tim untuk merumuskan SPO Spiritual Growth Facilitation, pelaksanaan meeting koodinasi untuk penyusunan SPO Spiritual Growth Facilitation, pelaksanaan seminar terkait SPO Spiritual Growth Facilitation, pelaksanaan kegiatan sosialisasi dan simulasi SPO Spiritual Growth Facilitation yang telah dirumuskan, serta penerapan SPO Spiritual Growth Facilitation pasien.Dilaksanakan pada bulan Juni -juli 2016menghasilkan suatu perubahan ditempat penelitian merupakan suatu hal yang sulit untuk dilakukan. Hal ini dirasakan peneliti khususnya dalam pembentukan standar prosedur operasional Pengembangan spiritual pasien. Dimana peneliti dan partisipan berusaha untuk memasukan konsep spiritual caring kedalam standar prosedur operasional pengembangan spiritual pasien yang ada di rumah sakit tersebut.

Selain itu, masalah internal rumah sakit juga cukup mempengaruhi kegiatan penelitian yang dilaksanakan khususnya dalam mengadakan diskusi dan penyampaian pendapat. Partisipan menjadi tidak termotivasi dan kurang mampu untuk menyampaikan pendapat saat diskusi dilakukan, sehingga peneliti harus bekerja keras untuk dapat waktu yang tepat untuk berdiskusi atau melakukan kegiatan dengan partisipan. Kegiatan yang dilakukan pada tahap ini yaitu pembentukan tim pelaksana pengembanan pertumbuhan spiritual pasien, pembuatan Standar Prosedur Operasional (SPO) dan format penilaian hasil pelaksanaan pengembangan spiritualitas pasien 
berbasis spiritualcaring, seminar dan sosialisasi SPO pengembangan spiritualitas pasien berbasis spiritualcaring, danpenerapan SPO serta observasi terhadap pelaksanaan berbasis caring. SPO pengembangan spiritualitas pasien berbasis spiritual caring Kegiatan pada tahap action, yaitu:

Pembentukan tim pelaksanapengembangan spiritualitas, Penelitisebelum melakukan pembentukan tim pelaksana pengembangan spiritualitas berbasis spiritualitascaring, peneliti bertemu dengan direktur dr. Maria MARS dan Kepala Diklat Rumah Sakit MedanSr.Estella FSE. Peneliti menjelaskan tentang penelitian yang dijalankan di Rumah Sakit Santa Elisabeth Medan. Pihak Struktural sangat mendukung dalam penelitian tersebut. Direktur mengatakan pelaksanaan SPOpengembangan spiritualitas pasien di Rumah Sakit tersebut belum ada standar, untuk itulah direktur tersebut berharap program yang akan dijalankan oleh peneliti dapat meningkatkan perilaku yang lebih baik untuk pengetahuan perawat khususnya mengenai SPO pengembangan spiritualitas pasien. Pembentukan tim pengembangan spiritualitas pasien dilakukan pada bulan Juni 2016 yang terdiri dari 5 orang yaitu kepala diklat, kepala ruangan Hemodialisa, Preceptor klinik, Perawat pelaksana Hemodilaisa Setelah tim terpilih, maka direktur menetapkan tim yang tersebut diatas dengan mengeluarkan surat keputusan tim pengembangan spiritualitas pasien.

Pembuatan Standar Prosedur Operasional (SPO) dan format penilaian hasil pelaksanaan SPO Pengembangan spiritual pasien, dalam pembuatan SPO ini pertama sekali SPO dibuat oleh peneliti namun belum bisa digunakan, oleh karena itu peneliti membuat seminar pada 17 Juni 2016 tentang pengembangan spiritual berbasis Spiritual caring dan untuk konsep caring dibawakan oleh Sr.Imelda Derang FSE, dimana tujuannya adalah untuk memberikan pengetahuan dan pemahaman kepada tim pelaksana pengembangan spiritual pasien sebelum diadakan diskusi untuk membuat SPO dan langkah selanjutnya yaitu melihat dan memahami kembali SPO yang ada di Rumah Sakit Santa Elisabeth, kemudian diskusi pembuatan SPO pengembangan spiritual pasien.

Proses kegiatan pada tahap acting mengalami perubahan dalam pelaksanaannya. Salah satu perubahan itu yaitu kegiatan seminar tentang caring yang dibawakan sendiri oleh peneliti. Menurut Semiawan (2010) bahwa pada tahap acting, peneliti merencanakan tindakan yang bersifat tentatif serta fleksibel terhadap perubahan yang akan disesuaikan dengan kondisi partisipan dan lingkungannya.

Standar prosedur operasional pengembangan spiritual yang telah dibentuk oleh tim dan peneliti terdapat unsur-unsur spiritualcaring dan pembinaan yang digunakan sebagai panduan dalam melaksanakan program tersebut. Beberapa yang harus dikerjakan oleh tim adalah mengidentifikasi kebutuhan dan tujuan perawat mengidentifikasi kompetensi perawat, mengidentifikasi pencapainan motivasi diri dan penilaian sikap perawat.

\section{PEMBAHASAN}

Pembahasan ini di sesuaikan dengan hasil yang didapat pada proses pelaksanaan reconnaissance, action research, out put dan out come pengembangan spiritual growth facilitation (SGF), manfaat yang diperoleh dari penelitian action research dan keterbatasan penelitian. Penelitian ini hanya menjalankan satu siklus action research selama 10 minggu dimulai dari bulan Juni sampai dengan Agustus 2016. Peneliti merupakan pemula dalam menggunakan action research. Pelaksanaan action research terdirin dari 4 tahapan yaitu planning, acting, observing, reflecting. Hal-hal yang dibahas pada bab ini antara lain adalah proses pengembangan spiritual growth facilitation (SGF), outcome spiritual growth facilitation (SGF), dampak penerapan spiritual growth facilitation $(S G F)$ terhadap perilaku perawat dan keterbatasan penelitian.

Pada tahap reconnaissance peneliti menemukan beberapa permasalah yang muncul dari pengembangan spiritual pasien yang dilakukan selama ini di Rumah Sakit Santa Elisabeth Medan yaitu 1) Mengenai pelaksanaan pengembangan spiritual pasien, dimana pelaksanaannya masih dianggap tidak sesuai, tidak ada SPO tetapi sebagaian sudah dilaksanakan sesuai standar yang ada, tidak ada materi yang diberikan, dan pelaksanaan evaluasi program hanya berdasarkan hasil diskusi secara lisan oleh kepala Diklat keperawatan dan kanit kanit rumah sakit tersebut. 2) Masalah terkait pengembangan spiritual pasien, dimana hasil wawancara tehnik FGD dengan beberapa partisipan ditemukan ada beberapa masalah yang terkait proses pembentukan pengembangan spiritual pasien yaitu terlalu sibuk, terjadi kesenjangan, tidak peduli, pelayanan tidak ramah kepada pasien, turnover selalu terjadi,2) Materi program, dalam program spiritul growth fasilitation di rumah sakit tersebut tidak ada pemberian materi secara terjadwal. Berdasarkan permasalah yang ditemukan maka partisipan mengungkapkan perlunya materi tentang komunikasi, pelayanan dan perilaku diajarkan terlebih dahulu. 4) Hambatan dalam pelaksanaan program yaitu kesibukan atau rutinitas, waktu, kurang peduli dan hambatan dari pihak atasan/ pimpinan. 5) Harapan mendatang, partisipan mengungkapkan sebaiknya SPO dijalankan dengan benar, diperlukan kepedulian, dan pemberian materi saat kerja dan dibuat pelatihan terkait spiritualias.

\section{SARAN}

Bagi pejabat struktural Rumah Sakit Santa Elisabeth Medan. Peneliti menyarankan agar membentuk tim yang berfungsi untuk melakukan evaluasi penerapan SGF baik untuk perawat secara berkesinambungan dan tahap selanjutnya, dan 
memotivasi perawat secara terus menerus menerapkan SPO yang telah dihasilkan dalam penelitian ini.

Bagi Peneliti Selanjutnya, diharapkan dapat menggunakan hasil penelitian ini menjadi salah satu data riset keperawatan (evidence based) yang dapat dikembangkan sebagai masukan penelitian selanjutnya dengan demikian keterbatasan dalam penelitian ini dapat diatasi pada siklus penelitian berikutnya pada penelitian action research. Peneliti menyarankan untuk menggunakan desain action research dengan melakukan sebanyak 3 siklus untuk hasil yang konsisten

\section{DAFTAR PUSTAKA}

Ayu Marta E. Purwaningsih, Asmaningrum N, Wantiyah (2013). Nurses Caring Behavior Relationships with Spiritual Fulfillment Inpatients at the Kaliwates Jember Hospital General. Artikel Ilmiah Hasil Penelitian Mahasiswa.

Barbara, et al.(2008). Fundamentals of Nursing : Consepts, Process, and Practice $8^{\text {th }}$ Ed. Unites States of America : PearsonEducation

Denzin, N, K, \& Lincoln, Y, S. (2009). Handbook of qualitative research. Edisi 1 bahasa Indonesia. Yogyakarta: Pustaka Belajar.

Denise L. Mitchell, Marsha J. Bennett,Linda ManfrinLedet, (2006). Spiritual Development of Nursing Students: Developing Competence to Provide Spiritual Care to Patients at the End of Life, Vol. 45, No. 9.

Hamid, et al. (2008). Spiritual Dalam Keperawatan. Jakarta : Widya Medika

Ibrahim Rahmat, Risanto Siswosudarmo, Ike Sureni (2002). Keefektifan Pemberian Bimbingan Spiritual Islami Pada Klien Terminal Terhadap Kecemasan dan Motivasi Hidup di Rumah Sakit Umum PKU Muhammadiyah Yogyakarta, (TESIS) Sekolah Pasca Sarjana UGM, Yogyakarta.

Kathleen M, (2011). Nursing Delegation and Management of Patient Care. Mosby/Elsevier

Kemmis, S, \& McTaggart, R. (1988). The action research planner. Victoria: Deakin University Press.

Kozier, Erb, G., Berman, A., \& Snyder, S.,J. (2010). Fundamental keperawatan: Konsep, proses, \& praktek. Edisi 7. Jakarta: EGC.

Lisa Astalos Chism, Morris A. Magnan, (2009). The Relationship of Nursing Students' Spiritual Care Perspectives to Their Expressions of Spiritual Empathy. Journal of Nursing Education; Volume 48 . Issue 11: 597-605

Polit, D.F. \& Beck, C.T. (2012). Nursing research generating and assessing evidence for nursing practice. (9th ed). Philadelphia: Lippincott.

Virgianti Nur Faridah. (2012). Pengaruh keperawataan spiritual emotional freedom technique (seft) islami terhadap tekanan darah penderita hipertensi usia 45-59 tahun di rsud dr. soegiri lamongan. Surya Jurnal Media Komunikasi Ilmu Kesehatan. Vol.02, No.XII ISSN : 1979-9128. 